Supporting Information for

\title{
IroT/MavN is a Legionella transmembrane Fe(II) transporter: metal se- lectivity and translocation kinetics revealed by in-vitro real-time transport
}

Sameera S. Abeyrathna ${ }^{1}$, Nisansala S. Abeyrathna ${ }^{1}$, Nathan Khoi Thai ${ }^{1}$, Prithwijit Sarkar ${ }^{2}$, Sheena D’Arcy $^{1,2}$, Gabriele Meloni ${ }^{1 *}$

${ }^{1}$ Department of Chemistry and Biochemistry, The University of Texas at Dallas, Richardson, TX 75080, USA

${ }^{2}$ Department of Biological Sciences, The University of Texas at Dallas, Richardson, TX 75080, USA

\section{AUTHOR INFORMATION}

*To whom correspondence should be addressed: gabriele.meloni@utdallas.edu 


\section{MATERIALS AND METHODS}

\section{Wild type LpIroT and mutant expression and purification}

A pET-52b(+) plasmid encoding for the codon optimized IroT homologue from Legionella pneumophila subsp. pneumophila (strain Philadelphia 1 / ATCC 33152 / DSM 7513); Gene: lpg_2815) was generated by Genscript Inc.. The construct was transformed in to E. coli BL21(DE3) GOLD competent cells (Agilent Technologies) for recombinant protein expression. O/N pre-cultures were inoculated at $1 \%(\mathrm{v} / \mathrm{v})$ in Terrific Broth (TB) media supplemented with $1 \%$ glycerol and grown in the presence of $50 \mu \mathrm{gL}^{-1}$ ampicillin at $37^{\circ} \mathrm{C}$ with orbital shaking $(140 \mathrm{rpm})$ to an $\mathrm{OD}_{600}=2$. Cells were subsequently cooled to 18 ${ }^{\circ} \mathrm{C}$ and protein expression was induced by addition of isopropyl thiogalactopyranoside (IPTG) to a final concentration of $0.30 \mathrm{mM}$. The protein was expressed for $19 \mathrm{~h}, 18^{\circ} \mathrm{C}$ at a shaking speed of $100 \mathrm{rpm}$.

Cells were harvested by centrifugation $\left(20 \mathrm{~min}, 4^{\circ} \mathrm{C}, 20000 \mathrm{x} \mathrm{g}\right.$ ) (Thermo Scientific Sorvall LYNX 6000 centrifuge). The cell pellet was suspended in buffer (20 mM Tris/ $\mathrm{HCl}, \mathrm{pH} 8,150 \mathrm{mM} \mathrm{NaCl}, 5 \mathrm{mM} \mathrm{MgCl}$, $30 \mu \mathrm{g} / \mathrm{mL}$ deoxyribonuclease I from bovine pancreas (Sigma-Aldrich), and 2x EDTA-free protease inhibitor cocktail tablets (Thermo Scientific). Cells were lysed with an ice-chilled microfluidizer at 20000 psi by flowing the cells through a Z-shaped diamond chamber for three cycles (Microfluidics M-110P). The lysate was subsequently centrifuged) to remove cell debris $\left(20 \mathrm{~min}, 4{ }^{\circ} \mathrm{C}, 20000 \mathrm{x} \mathrm{g}\right.$, Thermo Scientific Sorvall LYNX 6000 centrifuge). The membrane fraction containing LpIroT was isolated by ultracentrifugation $\left(1 \mathrm{~h}, 4{ }^{\circ} \mathrm{C}, 205,100 \mathrm{x}\right.$ g, Beckman Optima XPN80).

The membrane pellet was suspended in a resuspension buffer $(20 \mathrm{mM}$ Tris/ $\mathrm{HCl}, \mathrm{pH} 8,500 \mathrm{mM} \mathrm{NaCl}$, $1 \%(\mathrm{w} / \mathrm{v})$ glycerol supplemented with EDTA-free protease inhibitor cocktail) to a final membrane concentration corresponding to $1 \mathrm{~g}$ of cells per $1.0 \mathrm{~mL}$ of buffer. The membrane suspension was flash frozen in liquid $\mathrm{N}_{2}$ and stored at $-80{ }^{\circ} \mathrm{C}$ until purification.

Mutants were generated by site directed mutagenesis (Genscript Inc.) and expressed following the same protocol of $w t L p$ IroT.

$w t L p$ IroT and all mutants were purified by following the same IMAC chromatography methods with a Ni-NTA $5 \mathrm{~mL}$ HisTrap affinity column (GE Health care). For purification, $10 \mathrm{~mL}$ of the membrane suspension was diluted to a final volume of $50 \mathrm{~mL}$ with ice-cold protein extraction buffer $(20 \mathrm{mM}$ Tris/ $\mathrm{HCl}$, $\mathrm{pH} 8,500 \mathrm{mM} \mathrm{NaCl}, 35 \mathrm{mM}$ imidazole, $5 \mathrm{mM} \beta$-mercaptoethanol, and EDTA-free protease inhibitor cocktail (Thermo Scientific)). n-Tetradecylphospnocholine (Fos-Choline-14) was added to a final concentration of $1 \%(\mathrm{w} / \mathrm{v})$ in buffer and vigorously stirred for $1 \mathrm{~h}$ at $4{ }^{\circ} \mathrm{C}$ to extract membrane proteins. Residual membrane debris was removed by ultracentrifugation $\left(20 \mathrm{~min}, 4{ }^{\circ} \mathrm{C}, 205,100 \mathrm{xg}\right)$. The supernatant was loaded onto a pre-equilibrated Ni-NTA column with wash buffer $(20 \mathrm{mM}$ Tris/HCl, $\mathrm{pH} 8,500$ 
$\mathrm{mM} \mathrm{NaCl}, 35 \mathrm{mM}$ imidazole, $1 \mathrm{mM}$ dithiothreitol (DTT), 0.05\% (w/v) 7-cyclohexyl-1-heptyl- $\beta$-D-maltoside (Cymal-7)) using an AKTA Pure FPLC system (GE Health care). The column was washed with 50 CV wash buffer (20 mM Tris/HCl, pH 8, $500 \mathrm{mM} \mathrm{NaCl,} 35 \mathrm{mM}$ imidazole, $1 \mathrm{mM}$ dithiothreitol (DTT), $0.05 \%(\mathrm{w} / \mathrm{v})$ 7-cyclohexyl-1-heptyl- $\beta$-D-maltoside (Cymal-7) and bound protein was eluted with a linear imidazole gradient (0-100\%) obtained by mixing wash and elution buffer (20 mM Tris/HCl, pH 8, 500 $\mathrm{mM} \mathrm{NaCl}, 500 \mathrm{mM}$ imidazole, 0.05\% (w/v) Cymal-7, $1 \mathrm{mM}$ DTT) over $8 \mathrm{CV}$. The protein containing fractions were combined and the buffer immediately exchanged to final $20 \mathrm{mM}$ MOPS/NaOH, pH 7, 500 $\mathrm{mM} \mathrm{NaCl}, 1 \mathrm{mM}$ dithiothreitol (DTT), 0.05\% (w/v) Cymal-7, to remove imidazole on a HiPrep 26/10 desalting column (GE Healthcare). EDTA was added to a final concentration of $2 \mathrm{mM}$ and samples concentrated to $\sim 5-10 \mathrm{mg} / \mathrm{mL}$ using a 100,000 MWCO cutoff filter (Sartorious VIVASPIN 20) by centrifugation $\left(2100 \mathrm{x} \mathrm{g}, 4^{\circ} \mathrm{C}\right)$. Low molecular weight impurities and protein aggregates were removed by size exclusion chromatography using Superdex 200 10/300 or HiLoad Superdex 200 16/600 columns (GE Health care) in $20 \mathrm{mM}$ MOPS/NaOH, pH 7, $500 \mathrm{mM} \mathrm{NaCl}, 1 \mathrm{mM}$ dithiothreitol (DTT), 0.05\% (w/v) Cymal-7. After all the purification steps the protein was concentrated to $\sim 5-10 \mathrm{mg} / \mathrm{mL}$ for proteoliposome reconstitution and purity checked by SDS-PAGE (4-15\% Tris-Glycine Mini-PROTEAN gels, BioRad). Protein concentration was determined by absorption at $280 \mathrm{~nm}$ on a Nanodrop spectrometer (Thermo Scientific Nanodrop One) utilizing the extinction coefficient of $\varepsilon_{280}=122395 \mathrm{M}^{-1} \mathrm{~cm}^{-1}$ for the wild type protein (calculated based on Tyr and Trp content in the primary sequence using the Expasy Protparam software), or the respective extinction coefficient for mutants. All purified proteins were directly reconstituted in proteoliposomes without freezing.

\section{SEC-MALS analysis for molecular weight determination}

$20 \mu \mathrm{M}$ IroT was injected into a Superdex S200 Increase 10/300 GL column (GE healthcare) connected to miniDawn TREOS and Optilab T-rEX refractive index detectors (Wyatt). The column was pre-equilibrated with buffer (20 mM MOPS/NaOH pH=7, $100 \mathrm{mM} \mathrm{NaCl}, 1 \mathrm{mM}$ TCEP, 0.05\% (w/v) Cymal-7) and the data was analyzed using the ASTRA 7.02 software (for details: Wyatt Technology ASTRA Technical Note TN1007). UV extinction coefficients were calculated using Expasy Protparam (122395 $\mathrm{M}^{-1} \mathrm{~cm}^{-1)}$, and detergent $\mathrm{dn} / \mathrm{dc}$ values were obtained from Anatrace (Cymal-7: $\mathrm{dn} / \mathrm{dc}=0.1328 \mathrm{~mL} / \mathrm{g}$ ). The standard protein $\mathrm{dn} / \mathrm{dc}$ value of $0.185 \mathrm{~mL} / \mathrm{g}$ was used for the analysis as recommended by the manufacturer. Analysis revealed a polydispersity index (PDI) equal to $1.008 \pm 0.037 \%$. 


\section{LPIroT and mutants reconstitution in proteoliposomes}

Purified wild- type $L p$ IroT and all mutants were reconstituted at a 1:25 (w/w) protein-to-phospholipid ratio. E. coli polar lipid extract (Avanti Polar Lipids) and L- $\alpha$-phosphatidylcholine (from chicken egg; Avanti Polar Lipids) were used in a 3:1 ratio (w/w). The E. coli polar lipid extract and L- $\alpha$-phosphatidylcholine mixture dissolved in chloroform was dried under a nitrogen stream under rotation, and further dried overnight in a vacuum desiccator.

The lipids were subsequently hydrated and suspended in a $1 \mathrm{mM}$ TCEP solution (treated with Chelex (Bio-Rad) to remove metal contaminations. The suspended lipids were buffered to final $20 \mathrm{mM}$ MOPS/NaOH, pH 7, $100 \mathrm{mM} \mathrm{NaCl}, 1 \mathrm{mM}$ TCEP, by addition of a 10-times concentrated Chelex treated buffer solution (200 mM MOPS/NaOH, pH 7, $1 \mathrm{M} \mathrm{NaCl}, 1 \mathrm{mM} \mathrm{TCEP}$ ). The final lipid concentration was $25 \mathrm{mg} \mathrm{mL}^{-1}$.

Small unilamellar vesicles (SUVs) were prepared by three freeze thaw cycles in liquid nitrogen followed by 11 extrusions through polyethersulfone (PES) membranes of decreasing pore sizes ( $1 \mu \mathrm{m}, 400 \mathrm{~nm}$, and $200 \mathrm{~nm}$ ) using a $1 \mathrm{~mL}$ air tight syringe system (Avanti, Polar Lipids, Inc). Unilamellar vesicles were then destabilized by adding $0.02 \%(\mathrm{w} / \mathrm{v})$ Cymal- 7 and tilted for $1 \mathrm{~h}$ at room temperature.

To reconstitute the purified protein into the liposomes, a concentrated protein solution stock $(\sim 5-10$ $\mathrm{mg} / \mathrm{mL})$ was added to the detergent-destabilized liposomes on ice to a final 1:25 (w/w) protein:lipid ratio. Control liposomes were also generated by buffer addition to the detergent destabilized unilamellar lipid vesicles. The mixtures were tilted at $4{ }^{\circ} \mathrm{C}$ for $1 \mathrm{~h}$.

Bio-Beads (SM-2; Bio-Rad) were activated by sequential washing with methanol, ethanol and water followed by drying by vacuum filtration.

The detergent was removed by addition of the pre-activated Bio-Beads to the proteoliposomes and control liposomes to a final slurry Bio-Bead concentration of $40 \mathrm{mg} \mathrm{mL}^{-1}$, and tilted at $4^{\circ} \mathrm{C}$. Bio-beads were exchanged after $1,12,14$, and $16 \mathrm{~h}$, and the proteoliposomes and control liposomes were pelleted by ultracentrifugation at 160,000 $\mathrm{x}$ g in a Sorvall $\mathrm{mX120+}$ Micro-Ultracentrifuge. The proteoliposomes and control liposome pellets were collected and resuspended in $20 \mathrm{mM}$ MOPS/ $\mathrm{NaOH}, \mathrm{pH}$ 7, $100 \mathrm{mM} \mathrm{NaCl}$, $1 \mathrm{mM}$ TCEP (treated with Chelex) to a final lipid concentration of $25 \mathrm{mg} \mathrm{mL}^{-1}$ ( $L p \operatorname{IroT}=1 \mathrm{mg} \mathrm{mL}^{-1}$ ). Protein incorporation in the proteoliposomes was estimated by analyzing the ultracentrifugation supernatant and final suspended proteoliposomes by SDS-PAGE (4-15\% Tris-Glycine Mini-PROTEAN gels, BioRad). The proteoliposomes and control liposomes were flash frozen and stored at $-80^{\circ} \mathrm{C}$ prior to use for the transport assay. 
The number of $L p$ IroT molecules present in each proteoliposome particle was estimated by calculating the particle concentration based on the determined average SUVs diameter (determined by dynamic light scattering, see below) and the total lipid concentration. Assuming spherical particles, the total lipid head group area $\left(\mathrm{S}_{\mathrm{TOT}}\right)$ is the sum of the proteoliposome outer layer surface area $\left(\mathrm{S}_{\text {out }}\right)$ and the inner layer surface area $\left(S_{\text {in }}\right)$. Assuming a bilayer thickness of $3 \mathrm{~nm}(\mathrm{~h}=3 \mathrm{~nm}), \mathrm{S}_{\text {TOT }}$ could be estimated:

$\mathrm{S}_{\mathrm{TOT}}=\mathrm{S}_{\text {out }}+\mathrm{S}_{\mathrm{in}}=4 \pi \mathrm{r}^{2}+4 \pi(\mathrm{r}-\mathrm{h})^{2}$

The total number of lipid molecules per SUV $\left(\mathrm{N}_{\text {TOT }}\right)$ has been calculated assuming an average polar head surface $\left(\mathrm{S}_{\mathrm{L}}\right)$ of $0.7 \mathrm{~nm}^{2} /$ phospholipid:

$\mathrm{N}_{\mathrm{TOT}}=\mathrm{S}_{\mathrm{TOT}} / \mathrm{S}_{\mathrm{L}}$

The estimated MW for a single proteoliposome particle was calculated to determine the total SUV concentration in the samples, assuming the average phospholipid MW= $750 \mathrm{~g} / \mathrm{mol}$. By knowing the $L p$ IroT concentration in the preparations, the number of $L p$ IroT molecules per SUV was estimated.

\section{Dynamic Light Scattering measurements}

Fluozin-3 encapsulated proteoliposomes and control liposomes were analyzed by UV-Vis dynamic light scattering (DLS) with Zetasizer Nano ZS (Malvern Panalytical) to determine the vesicle size and the size distribution. Fluozin-3 encapsulated proteoliposomes and controls were prepared and harvested as descried. Measurements were collected on samples loaded in a disposable micro cuvette at $25.0^{\circ} \mathrm{C}$ using a $633 \mathrm{~nm}$ laser wavelength, $175^{\circ}$ scattering angle and calculated using a medium refractive index of 1.33 and a material refractive index of 1.51. The determined control liposome and IroT proteoliposome PDIs, are 0.195 and 0.275 respectively.

\section{Fluozin-3 encapsulation in proteoliposome lumen}

To encapsulate in the proteoliposome lumen the fluorescence chelator Fluozin-3 (Invitrogen), proteoliposomes were diluted to a final lipid concentration of $12.5 \mathrm{mg} \mathrm{mL}^{-1}$ in transport buffer $(20 \mathrm{mM}$ MOPS/NaOH, pH 7, $100 \mathrm{mM} \mathrm{NaCl,} 1 \mathrm{mM}$ TCEP). Fluozin-3 was added to the proteoliposome suspension to a final concentration of $10 \mu \mathrm{M}$ and encapsulated by three subsequent freeze-thaw cycles in liquid $\mathrm{N}_{2}$. Fluozin-3 containing SUVs were prepared by sequential 11 extrusions through $1 \mu \mathrm{m}, 400 \mathrm{~nm}$, and 200 nm membrane filters using an air tight syringe system.

Free Fluozin-3 was removed via proteoliposome ultracentrifugation at $160000 \mathrm{x} g$ in a Sorvall $\mathrm{mX120+}$ Micro-Ultracentrifuge. The proteoliposome pellets were washed by an additional suspension and ultracentrifugation round. The proteoliposome pellets were suspended in transport assay buffer $(20 \mathrm{mM}$ 
MOPS/NaOH, pH 7, $100 \mathrm{mM} \mathrm{NaCl,} 1 \mathrm{mM}$ TCEP) to determine in- vitro transition metal transport. Control liposomes were prepared in the same manner with protein-free liposomes.

\section{In vitro $\mathrm{Fe}^{2+}$ transport assay}

MilliQ water and buffer solutions (20 mM MOPS/NaOH, pH 7.0, $100 \mathrm{mM} \mathrm{NaCl,} 1 \mathrm{mM}$ TCEP) were made oxygen-free on a Schlenk-line by at least three vacuum/nitrogen cycles. All $\mathrm{Fe}^{2+}$ stock solutions were freshly prepared prior to each experiment in an anaerobic glove box purged with constant $\mathrm{N}_{2}$ flow. To prepare the $\mathrm{Fe}^{2+}$ stock solution series, a $100 \mathrm{mM} \mathrm{Fe}^{2+}$ solution was prepared by dissolving iron (II) sulfate heptahydrate (ACROS ORGANICS) in miliQ water and 10x $\mathrm{Fe}^{2+}$ stocks for transport assays were prepared by serial dilution in transport buffer. All stock solutions were stored in sealed tubes prior to use in the proteoliposome assays.

The Fe(II) transport assays were conducted at $25^{\circ} \mathrm{C}$ in a sub-micro quartz cell (Starna Cells) in a spectrofluorometer (Horiba scientific Fluoromax-4), using excitation and emission wavelengths of 480 and $515 \mathrm{~nm}$, respectively. $108 \mu \mathrm{L}$ of the Fluozin-3 encapsulated LpIrot proteoliposomes were placed in the quartz cuvette and the baseline florescence was measured for $50 \mathrm{~s}$ prior to $\mathrm{Fe}^{2+}$ addition. $\mathrm{Fe}(\mathrm{II})$ transport was initiated by addition of a freshly prepared $\mathrm{Fe}^{2+}$ solution $(12 \mu \mathrm{L})$ and the fluorescence change monitored for $600 \mathrm{~s}$ with $0.5 \mathrm{~s}$ interval time. Measurements on control protein-free liposomes were conducted with the same procedure.

$\mathrm{Fe}^{2+}$ transport was determined as $\Delta \mathrm{F} / \mathrm{F}_{0}$, where $\Delta \mathrm{F}$ is the difference between the fluorescence measured at time $t\left(\mathrm{~F}_{\mathrm{t}}\right)$ and the fluorescence recorded immediately before $\mathrm{Fe}^{2+}$ addition $\left(\mathrm{F}_{0}\right)$.

\section{$\mathrm{Fe}^{2+}$-coupled proton counter-transport monitored with pyranine}

$\mathrm{Fe}^{2+}$-dependent $\mathrm{H}^{+}$counter-transport was determined on $w t L p$ IroT proteoliposomes and control liposomes by encapsulating the fluorescent $\mathrm{pH}$-dependent indicator pyranine (Alfa Aesar) in the lumen. Prior to each experiment $w t L p$ IroT proteoliposomes and control liposomes were ultracentrifuged at 160,000 x $\mathrm{g}$ for 45 min and resuspended in transport assay buffer $(10 \mathrm{mM}$ MOPS/NaOH, pH 7.0, $100 \mathrm{mM} \mathrm{NaCl}, 1 \mathrm{mM}$ TCEP) to a final lipid concentration of $12.5 \mathrm{mg} \mathrm{mL}^{-1}$. Pyranine was added to a final concentration of 1 $\mathrm{mM}$ and encapsulated by three freeze-thaw cycles in liquid $\mathrm{N}_{2}$. Pyranine-encapsulated SUVs were prepared by extrusion as described above. After 2 washing steps, proteoliposomes and control liposomes were resuspended in transport assay buffer (10 mM MOPS/NaOH, $100 \mathrm{mM} \mathrm{NaCl}, 1 \mathrm{mM}$ TCEP) to a final lipid concentration of $25 \mathrm{mg} \mathrm{mL} \mathrm{mL}^{-1}$. Oxygen-free $\mathrm{Fe}^{2+}$ stock solutions were freshly prepared in anaerobic atmosphere prior to each experiment. Kinetic measurements were carried out on a stopped-flow spectro- 
fluorometer at $25^{\circ} \mathrm{C}(\mathrm{SX}-20$, Applied Photophysics), by mixing equal volumes $(70 \mu \mathrm{L})$ of $w t L p$ IroT proteoliposomes (or control liposomes) with $40 \mu \mathrm{M} \mathrm{Fe}^{2+}$ stock solutions, and the fluorescence kinetic traces recorded using $\lambda_{\mathrm{exc}}=450 \mathrm{~nm}$ in the presence of an emission filter with $\lambda_{\text {cut-off }}>515 \mathrm{~nm}$. Fluorescence spectra was recorded for $601 \mathrm{~s}$.

\section{Metal selectivity transport assays}

To determine LpIroT selectivity, the transport assay was conducted utilizing the same procedure as described for Fe(II) with different metal stocks. Buffers were made oxygen-free by at least three vacuum/nitrogen cycles on a Schlenk-line and $\mathrm{Ni}^{2+}, \mathrm{Co}^{2+}, \mathrm{Fe}^{2+}$ and $\mathrm{Mn}^{2+}$ stock solutions were freshly prepared in an anaerobic glove box purged with constant $\mathrm{N}_{2}$ flow. Nickel(II) chloride hexahydrate (Alfa Aesar), cobalt(II) chloride hexahydrate (Alfa Aesar), iron(II) sulfate heptahydrate (ACROS ORGANICS), and manganese chloride tetrahydrate were utilized, respectively. $\mathrm{Zn}^{2+}$ and $\mathrm{Cd}^{2+}$ stocks were prepared in a similar manner using $\mathrm{ZnCl}_{2}$ and $\mathrm{CdCl}_{2}$ under ambient conditions (air atmosphere, $20^{\circ} \mathrm{C}$ ).

To test $\mathrm{Fe}^{2+}$ selectivity over $\mathrm{Fe}^{3+}$, transport assays were conducted with Fluozin-3 excluding the reducing agent TCEP from the assay buffer. Buffer exchange on LpIroT proteoliposomes and control liposomes was performed by collecting the SUVs by ultracentrifugation $\left(160,000 \mathrm{x} \mathrm{g}, 45 \mathrm{~min}, 4^{\circ} \mathrm{C}\right)$ followed by resuspension in TCEP-free buffer (20 mM MOPS/ $\mathrm{maOH} \mathrm{pH}=7.0,100 \mathrm{mM} \mathrm{NaCl})$. Ferric ammonium citrate (MP Biomedicals,LCC) stock solutions were prepared and transport assays perfomed at $\mathrm{Fe}^{3+}=$ $5 \mu \mathrm{M}$. For comparison, $\mathrm{Fe}^{2+}$ transport was tested under the same conditions in the absence of reducing agents.

\section{Fluozin-3 titration with $\mathrm{M}^{2+}$ ions.}

$\mathrm{M}^{2+}\left(\mathrm{M}^{2+}=\mathrm{Mn}(\mathrm{II}), \mathrm{Fe}(\mathrm{II}), \mathrm{Co}(\mathrm{II}), \mathrm{Ni}(\mathrm{II}), \mathrm{Zn}(\mathrm{II})\right.$ or $\left.\mathrm{Cd}(\mathrm{II})\right)$ stock solutions were freshly prepared prior to each titration experiment as described for metal selectivity transport assays. Fluozin-3 solutions were prepared in Chelex-treated transport assay buffer. Metal titrations were conducted in a $1 \mathrm{~mL}$ sub-micro quartz fluorometer cell (Starna Cells) using a Fluoromax-4 spectrofluorometer (Horiba scientific). $10 \mu \mathrm{M}$ Fluozin-3 was placed in the quartz cell and the initial florescence measured for $50 \mathrm{~s}\left(\lambda_{\mathrm{exc}}=480 \mathrm{~nm} ; \lambda_{\mathrm{em}}=\right.$ $515 \mathrm{~nm}$ ). After $50 \mathrm{~s}$, the $\mathrm{M}^{2+}$ solutions were added and resulting fluorescence intensity was measured. Similarly, titration experiments were performed in the presence of $12.5 \mathrm{mg} / \mathrm{mL}$ liposomes in the assay buffer to test the effect of lipids on the dye turn-on response to different $\mathrm{M}^{2+}$ ions.

Emission spectra for Fluozin-3 $(10 \mu \mathrm{M})$ in the presence of equimolar $\mathrm{M}^{2+}$ concentrations $(10 \mu \mathrm{M})$ were collected between $490-650 \mathrm{~nm}\left(\lambda_{\text {exc. }}=480 \mathrm{~nm}\right)$ on samples prepared as above. 
Similar experiments were also conducted with Ferric ammonium citrate solutions to test the response of Fluozin-3 to $\mathrm{Fe}^{3+}$.

\section{His ${ }_{10}$-tag removal}

Purified $w t L p$ IroT and $\Delta \mathrm{C}$-term IroT were rebuffered in $20 \mathrm{mM} \mathrm{MOPS} / \mathrm{NaOH}, \mathrm{pH}=7.0,100 \mathrm{mM} \mathrm{NaCl}$, $1 \mathrm{mM}$ TCEP, $0.05 \%$ (w/v) Cymal-7). Protein concentration was adjusted to $0.5 \mathrm{mg} \mathrm{mL}^{-1}$. Bovine Thrombin (EMD Millipore Crop.) was added (4 Units/mg IroT) and cleavage carried out at $25^{\circ} \mathrm{C}$ for $8 \mathrm{~h}$, with tilting. Imidazole was then added to the mixture to a final concentration of $35 \mathrm{mM}$. The mixture was subsequently incubated for $1 \mathrm{~h}$ with $2 \mathrm{~mL}$ of Ni-NTA Resin (Biosciences) equilibrated in the same buffer. Uncleaved protein bound to the resin was removed by centrifugation and $2 \mathrm{mM}$ EDTA added to the supernatant. Impurities and protein aggregates were removed by size-exclusion chromatography using a HiLoad Superdex 200 16/600 column and eluted with chelex-treated buffer (20 mM MOPS/NaOH, pH = 7.0, $100 \mathrm{mM} \mathrm{NaCl}, 1 \mathrm{mM}$ TCEP, 0.05\% (w/v) Cymal-7).

\section{Determination of overall apparent dissociation constants by ligand competition.}

The overall apparent IroT-Fe ${ }^{2+}$ dissociation constants $\left(\mathrm{K}_{\mathrm{D}}\right)$ were determined by ligand competition using MagFura-2 (MF-2) using previously developed methods ${ }^{1-3}$. Experiments were carried out in a $1.0 \mathrm{~cm}$ quartz cuvette using chelex-treated oxygen-free buffer $(25 \mathrm{mM} \mathrm{MOPS} / \mathrm{NaOH}, \mathrm{pH}=7.5,150 \mathrm{mM} \mathrm{NaCl}$, $1 \mathrm{mM}$ TCEP, 0.05\% (w/v) Cymal-7). All the mixing steps were conducted in an anaerobic glove-box purged with $\mathrm{N}_{2}$. Tag-free $w t L p$ IroT and MF-2 were mixed to final $20 \mu \mathrm{M}$ and $10 \mu \mathrm{M}$, respectively, in a quartz cuvette. The actual final MF-2 concentration was determined using $\varepsilon_{366}=29900 \mathrm{M}^{-1} \mathrm{~cm}^{-1} 1,2$. UVVis spectra were recorded on a Cary $300 \mathrm{UV}-$ Vis Spectrophotometer (Agilent). $\mathrm{Fe}^{2+}$ competition titrations were performed in an anaerobic glovebox, by sequential $\mathrm{Fe}^{2+}$ addition in $2 \mu \mathrm{M}$ increments and the resulting absorption spectra recorded. Similar determination were carried out with $\Delta \mathrm{C}$-term IroT.

Overall apparent $K_{D}$ determination was performed as described previously ${ }^{2,3}$. Briefly, the variables $Q$ and $\mathrm{P}$ are calculated using equation 1 and 2.

$$
\mathrm{Q}=\frac{\varepsilon-\varepsilon_{\mathrm{IL}}}{\varepsilon_{\mathrm{I}}-\varepsilon} \quad \text { (1) } \quad \mathrm{P}=\mathrm{L}_{\mathrm{t}^{-}}{ }^{1} / \mathrm{QK}_{\mathrm{I}}{ }^{-\mathrm{I}_{\mathrm{t}}} / \mathrm{Q}+1
$$

Free indicator to metal bound indicator ratio is given by Q. $\varepsilon, \varepsilon_{\mathrm{I}}$ and $\varepsilon_{\mathrm{IL}}$ are the extinctions coefficients of observed, free and MF-2-Fe ${ }^{2+}$ bound states. $\mathrm{P}$ is the concentration of IroT-Fe ${ }^{2+}$ complex. $\mathrm{I}_{\mathrm{t}}$ is total MF-2 concentration and $\mathrm{K}_{\mathrm{I}}$ is the association constant of $\mathrm{MF}-2-\mathrm{Fe}^{2+}$ complex $\left(\mathrm{K}_{\mathrm{D}}=1.5 \mu \mathrm{M}\right)^{1}$. Assuming a 1:1 protein-metal complex formation, variables are related as in equation 3. 


$$
\frac{\mathrm{S}_{\mathrm{t}}}{\mathrm{P}}=\frac{\mathrm{K}_{\mathrm{I}}}{\mathrm{K}_{\text {prot }}} \mathrm{Q}+1
$$

Dissociation constant $\left(\mathrm{K}_{\mathrm{D}, \mathrm{Fe}(\mathrm{II})}\right)$ for the IroT-Fe ${ }^{2+}$ complex can be estimated by plotting $\mathrm{S}_{\mathrm{t}} / \mathrm{P}$ vs $\mathrm{Q}$. $\mathrm{S}_{\mathrm{t}}$ is the total protein concentration. $\mathrm{K}_{\text {prot }}$ is the $\mathrm{Fe}(\mathrm{II})$ association constant for IroT ${ }^{2,3}$.

1. Patel, S.J., et al. Fine-tuning of Substrate Affinity Leads to Alternative Roles of Mycobacterium tuberculosis Fe ${ }^{2+}$-ATPases. J. Biol. Chem., 291, 11529-11539 (2016).

2. Walkup, G.K. \& Imperiali, B. Fluorescent Chemosensors for Divalent Zinc Based on Zinc Finger Domains. Enhanced Oxidative Stability, Metal Binding Affinity, and Structural and Functional Characterization. J. Am. Chem. Soc. 119, 3443-3450 (1997).

3. Connors, K.A. Binding Constants: The Measurement of Molecular Complex Stability, (WileyInterscience: New York, 1987). 


\section{Figure S1}

A

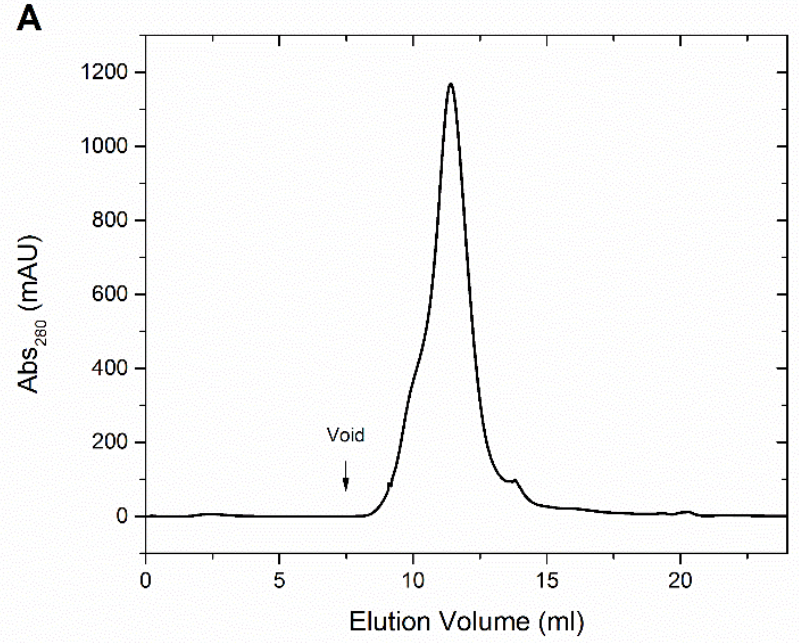

B

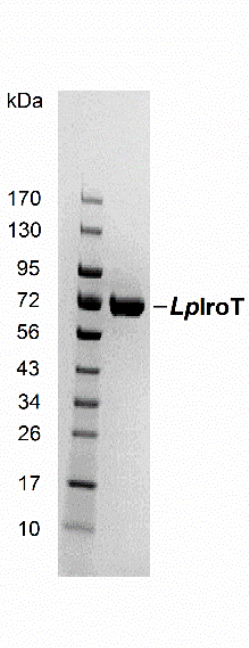

C

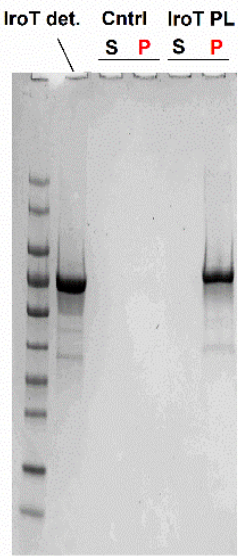

Figure S1: (A) Size exclusion chromatography elution profile for $w t L p$ IroT purified in in Cymal-7 micelles. (B) SDS-PAGE analysis of $L p$ IroT upon SEC. (C) SDS-PAGE analysis of $w t L p I r o T$ incorporation in pelleted proteoliposomes (P) compared to non-incorporated protein (S, supernatant) vs. wtLpIroT-Cymal-7 micelles, and corresponding analysis of control liposomes. 


\section{Figure S2}

A

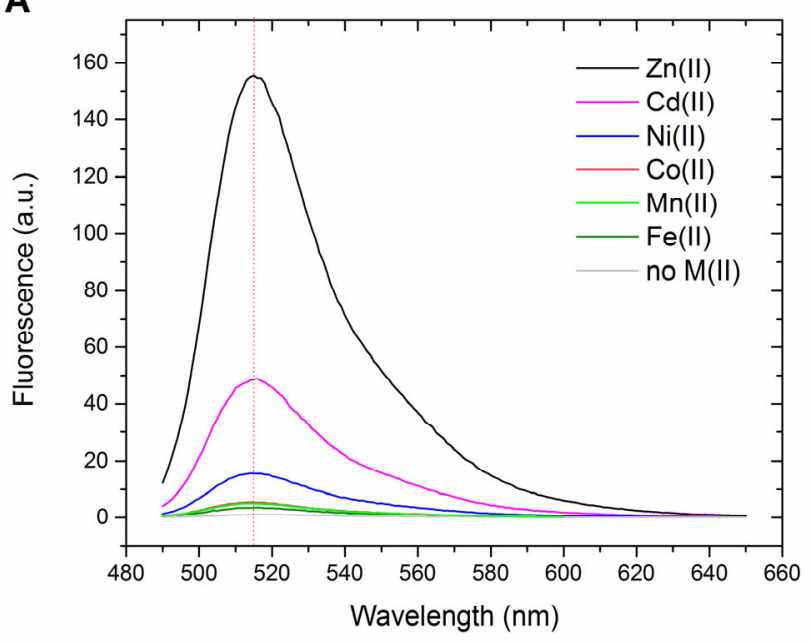

B

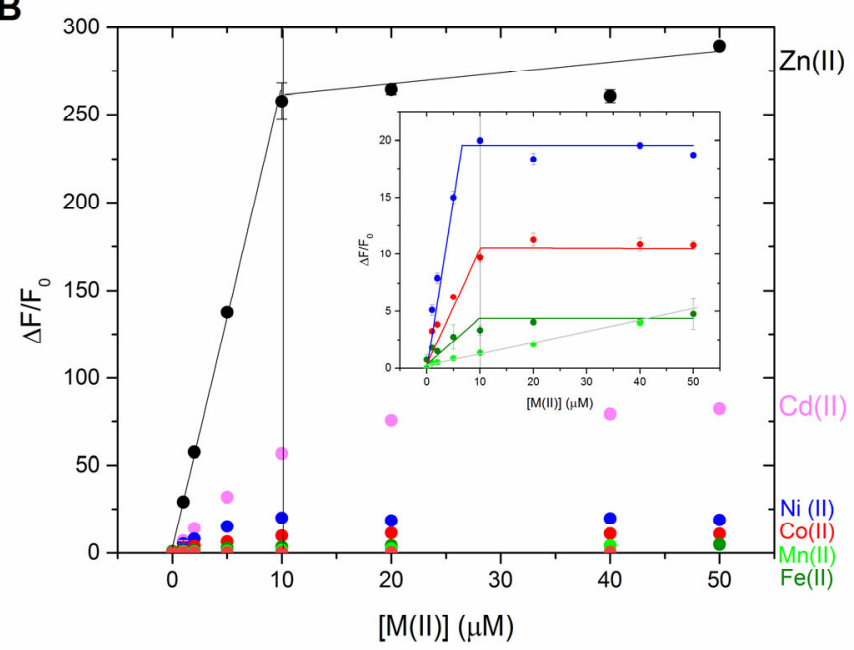

Figure S2 (A) Fluozin-3 (10 $\mu \mathrm{M})$ fluorescence emission turn-on response in the presence of equimolar concentration of $\mathrm{Mn}(\mathrm{II}), \mathrm{Fe}(\mathrm{II}), \mathrm{Co}(\mathrm{II}), \mathrm{Ni}(\mathrm{II}), \mathrm{Zn}(\mathrm{II})$ and $\mathrm{Cd}(\mathrm{II})\left(\lambda_{\mathrm{exc}}=480 \mathrm{~nm}\right)$ in absence of liposomes. (B) Fluozin-3 $(10 \mu \mathrm{M})$ fluorescence turn-on response upon metal titration $\left(\lambda_{\mathrm{exc}}=480 \mathrm{~nm} ; \lambda_{\mathrm{em}}=515 \mathrm{~nm}\right.$, line color corresponding to Figure $2 \mathrm{~A}$ ) in absence of liposomes, reported as $\left(\mathrm{F}-\mathrm{F}_{0}\right) / \mathrm{F}_{0}$ (where $\mathrm{F}_{0}$ is the Fluozin3 fluorescence in absence of metals). The response to $\mathrm{Mn}(\mathrm{II}), \mathrm{Fe}(\mathrm{II}), \mathrm{Co}(\mathrm{II})$ and $\mathrm{Ni}(\mathrm{II})$ is enlarged in the Inset. 


\section{Figure S3}
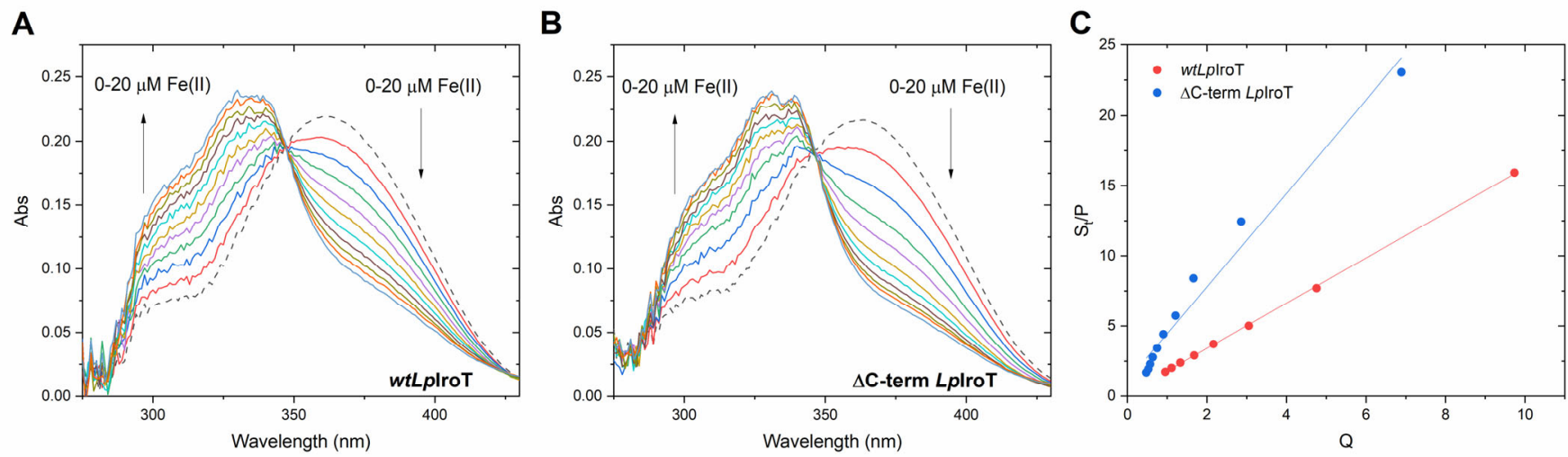

Figure S3 Competition of MagFura-2 (MF-2) for Fe (II) with IroT. (A) Representative absorption spectra obtained for the titration of $10 \mu \mathrm{M} \mathrm{MF-2} \mathrm{and} 20 \mu \mathrm{M} w t L p$ IroT with increasing concentrations of Fe(II) $(0-20 \mu \mathrm{M} ; 2 \mu \mathrm{M}$ increments) in $25 \mathrm{mM}$ MOPS-NaOH, $\mathrm{pH}=7.5,150 \mathrm{mM} \mathrm{NaCl}, 1 \mathrm{mM}$ TCEP, $0.05 \%$ (w/v) Cymal-7. (B) Representative absorption spectra obtained for the titration of $10 \mu \mathrm{M}$ MF-2 and 20 $\mu \mathrm{M} \Delta \mathrm{C}$-term $L p$ IroT. (C) Representative plots obtained for fitting of $\mathrm{S}_{t} / \mathrm{P} v s$. Q values calculated as described in Materials and Methods. 


\section{Figure S4}

A

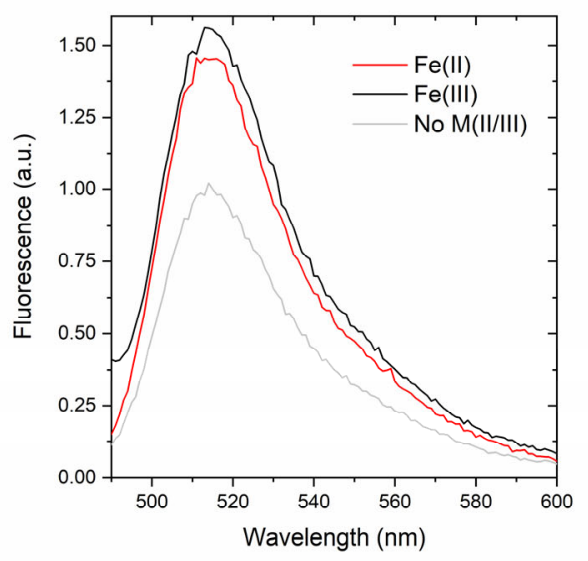

B

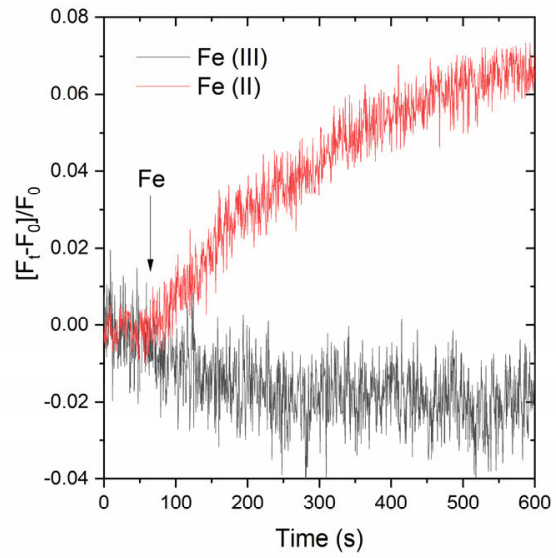

Figure S4 $w t L p$ IroT substrate selectivity towards Fe(II) over Fe(III) (A) Fluozin-3 (10 $\mu \mathrm{M})$ fluorescence emission turn-on response for equimolar concentrations of Fluozin-3 and $\mathrm{Fe}(\mathrm{II})$ or $\mathrm{Fe}$ (III) $\left(5 \mu \mathrm{M}\right.$; $\lambda_{\mathrm{exc}}=$ $480 \mathrm{~nm}$ ) in the presence of $200 \mathrm{~nm}$ liposomes (PC/polar lipids 1:3 w/w, $12.5 \mathrm{mg} / \mathrm{ml})$. Representative fluorescence real-time transport traces in $L p$ IroT proteoliposomes with encapsulated Fluozin-3 for Fe(II) and $\mathrm{Fe}(\mathrm{III})$ in the absence of TCEP (20 mM MOPS/NaOH, $\mathrm{pH}=7.0,100 \mathrm{mM} \mathrm{NaCl})$. 


\section{Figure S5}

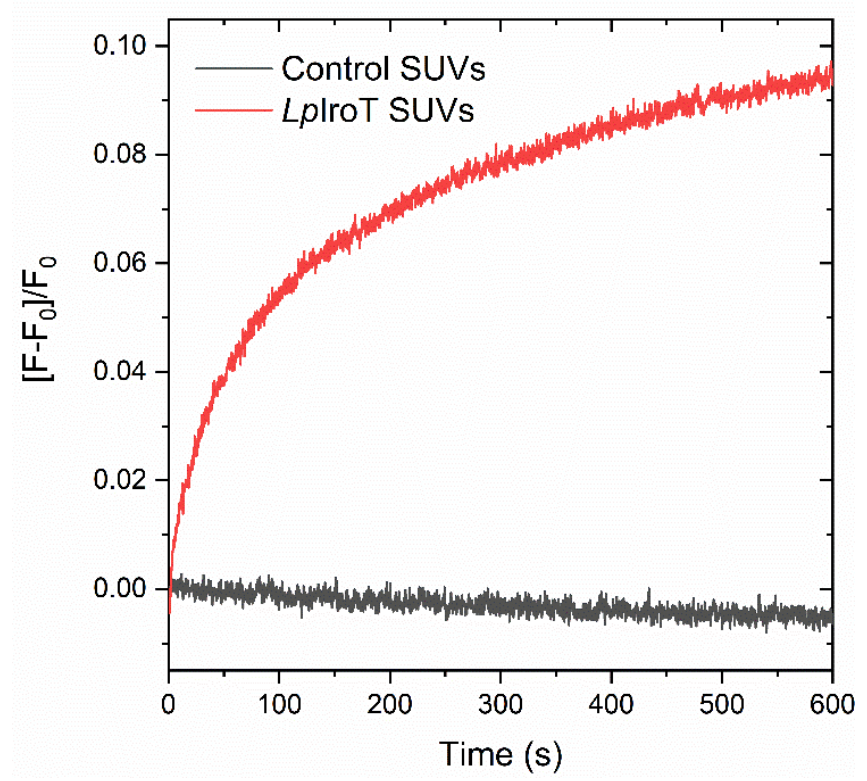

Figure S5 Fluorescence-detected $\left(\lambda_{\mathrm{exc}}=450 \mathrm{~nm} ; \lambda_{\mathrm{em}}>515 \mathrm{~nm}\right)$ proton counter-transport monitored by pyranine encapsulation in control and $L p$ IroT proteoliposomes exposed to $\mathrm{Fe}(\mathrm{II})=20 \mu \mathrm{M}$ (average of two independent replicates). 
Figure S6

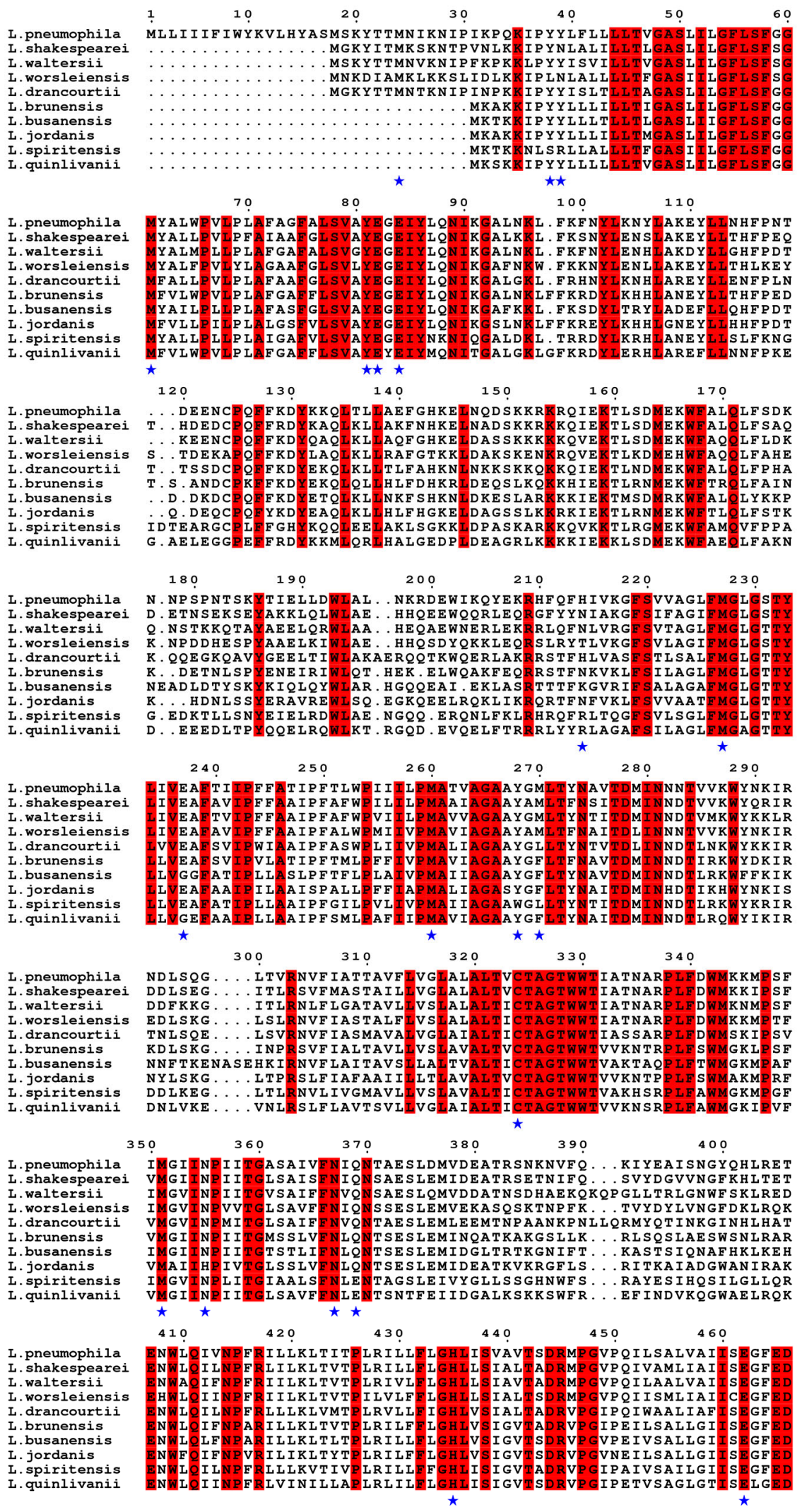




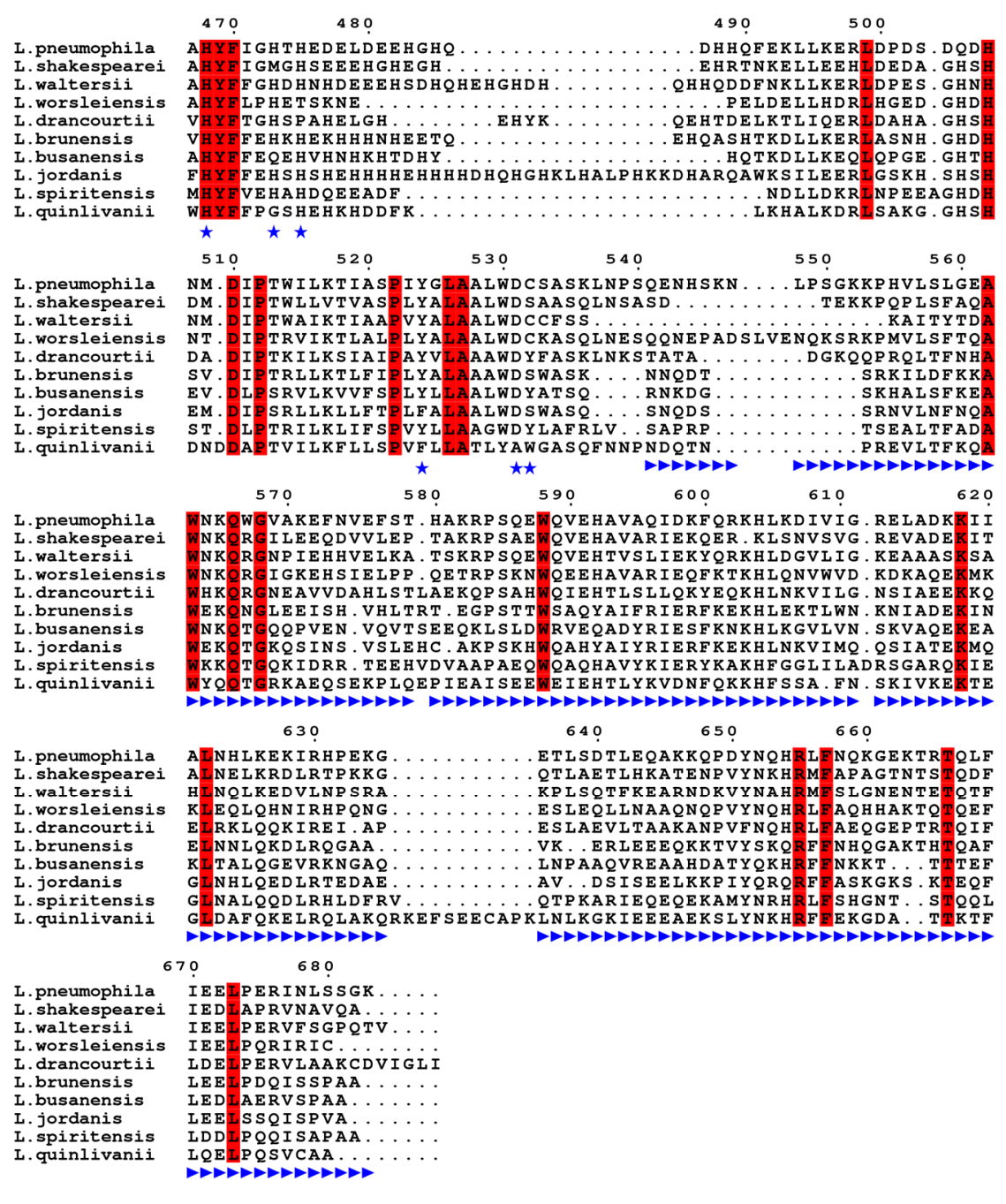

Figure S6 Sequence alignment of 10 Legionella IroT/MavN homologues. Uniprot Accession Numbers: L. pneumophila (Q5ZRR5), L. shakespearei (A0A0W0YRI1), L. waltersii (A0A0W1A4L9), L. worsleiensis (A0A0W1AF00), L. drancourtii (G9ETW3), L. busanensis (A0A378JX52), L. brunensis (A0A0W0S175), L. jordanis (A0A0W0VD72), L. spiritensis (A0A0W0Z6K6), L. quinlivanii (A0A0W0Y5F3). Fully conserved residues are highlighted in red, potential Fe (II) coordinating residues mutated in this work are indicated with blue stars, and amino acids (541-683) absent in $\Delta \mathrm{C}$-term $L p \operatorname{IroT}$ are indicated in blue triangles. Figure generated with ESPript 3.0 (http://espript.ibcp.fr/ESPript/ESPript). 


\section{Figure S7}

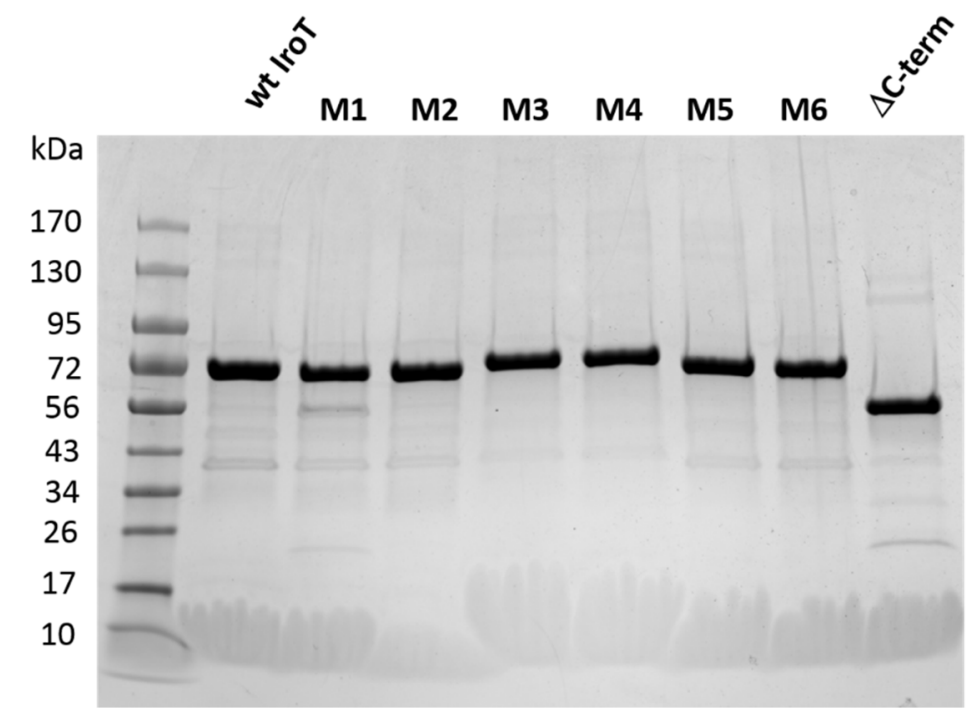

Figure S7 SDS-PAGE analysis of $w t L p$ IroT and mutants (M1-6 and $\Delta$ C-term) reconstituted in proteoliposomes utilized for Fe(II) transport assays. 


\section{Figure S8}

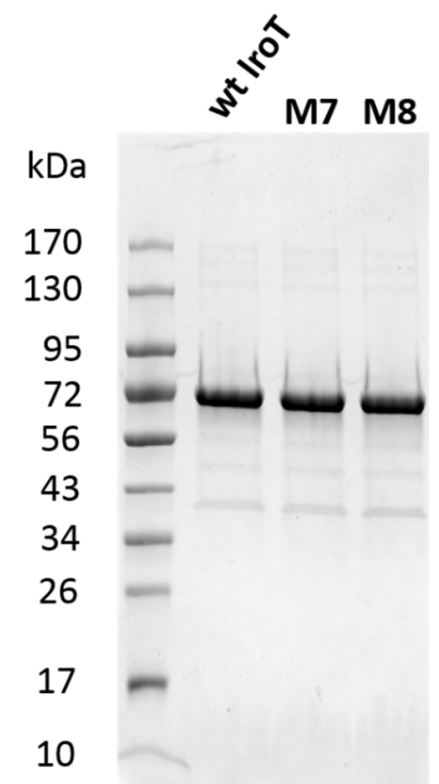

Figure S8 SDS-PAGE analysis of wtLpIroT and mutants M7 and M8 (E462ALpIroT and E462A_H468A_H473A_H475ALpIroT respectively) reconstituted in proteoliposomes utilized for Fe(II) transport assays. 


\section{Table S1}

$L p$ IroT mutants and corresponding location in the $L p$ IroT topology model

\begin{tabular}{|c|c|c|c|c|c|c|}
\hline $\begin{array}{l}\text { Mutant } \\
\text { Name }\end{array}$ & Mutant position & $\begin{array}{c}\text { Host -side } \\
\text { soluble do- } \\
\text { mains }\end{array}$ & $\begin{array}{l}\text { LCV-side } \\
\text { soluble } \\
\text { domains } \\
\end{array}$ & $\begin{array}{l}\text { Interface } \\
\text { TM -host } \\
\text { cytoplasm }\end{array}$ & $\begin{array}{l}\text { Interface } \\
\text { TM-LCV }\end{array}$ & $\begin{array}{l}\text { TM heli- } \\
\text { ces core }\end{array}$ \\
\hline M1 & E82A_E84A_H214A_D531A_C532A & & & $\mathbf{X}$ & & \\
\hline M2 & E82A E84A H214A & & & $\mathbf{X}$ & & \\
\hline M3 & $\begin{array}{l}\text { M24A_Y38A_Y39A_Y81A_E82A } \\
\text { E84A_H214_Y268A_M270A_N367A- } \\
\text { Q369A_D531A_C532A }\end{array}$ & & & $\mathbf{X}$ & & \\
\hline M4 & M227A_M260A_N355A_Y524A & & & & & $\mathbf{X}$ \\
\hline M5 & M61A_E237A_C324A_M351A_H435A & & & & $\mathbf{X}$ & \\
\hline M6 & E237A_C324A_H435A & & & & $\mathbf{X}$ & \\
\hline M7 & $\mathrm{E} 462 \mathrm{~A}$ & & $\mathbf{X}$ & & & \\
\hline M8 & E462A H468A H473A H475A & & $\mathbf{X}$ & & & \\
\hline $\begin{array}{l}\Delta C- \\
\text { term }\end{array}$ & $\begin{array}{l}\text { Deletion of C-terminal soluble } \\
\text { domain }\left(\Delta_{541-683}-L p \text { IroT }\right)\end{array}$ & $\mathbf{X}$ & & & & \\
\hline
\end{tabular}




\section{Table S2}

Apparent Michaelis-Menten parameters for Fe(II) translocation in proteoliposomes obtained by fitting the maximum fluorescence intensity change $\left(\Delta \mathrm{F} / \mathrm{F}_{0}\right)$ as function of $\mathrm{Fe}(\mathrm{II})$ concentrations for $w t L p$ IroT and mutants

\begin{tabular}{|c|c|c|}
\hline & $\mathbf{K}_{\mathbf{M}, \mathbf{F e}(\mathbf{I I})}(\boldsymbol{\mu M})$ & $\left(\Delta \mathbf{F} / \mathbf{F}_{\mathbf{0}}\right)_{\mathbf{M A X}}$ \\
\hline wtLpIroT & $5.99 \pm 1.70$ & $0.25 \pm 0.02$ \\
\hline LpIroT-M1 & $>25 \mu \mathrm{M}$ & $0.20 \pm 0.10$ \\
\hline LpIroT-M2 & $>25 \mu \mathrm{M}$ & $0.30 \pm 0.10$ \\
\hline LpIroT-M3 & n.d. ${ }^{\mathrm{a}}$ & $0.10 \pm 0.02$ \\
\hline LpIroT-M4 & $23.0 \pm 14.8$ & $0.22 \pm 0.7$ \\
\hline LpIroT-M5 & n.d. & $0.06 \pm 0.01$ \\
\hline LpIroT-M6 & n.d. & $0.06 \pm 0.01$ \\
\hline
\end{tabular}

a. not determined, the mutant shows minimal transport activity. 